\title{
Creación artística y ética. Montaje a partir de Thomas Mann
}

\section{Crescenciano Grave}

\begin{abstract}
Al poeta le compete la representación. Alcanza ésta su apogeo cuando compite con la realidad, es decir, cuando sus descripciones cobran, merced al ingenio, vida tal que pueden pasar por reales para todo el
\end{abstract}

mundo.

Goethe

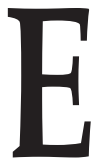

1 mundo que la literatura instaura es una representación que se levanta desde el ejercicio de la imaginación creadora mediante la cual se perfilan deseos, sentimientos, caracteres y situaciones que, provenientes de una idealización verosímil del mundo de la vida, poseen el poder de suscitar la reflexión sobre lo que realmente acontece en ese mundo. La gran obra de arte literario no es nunca una pérdida de realidad; es una provocación que nos invita a penetrarla reflexivamente para alumbrar, desde ella, significaciones que no nos impidan seguir afirmando la vida. En su peculiar configuración del lenguaje, la creación literaria tiende lazos no sólo con otras actividades del pensamiento que también se expresan lingüísticamente, como la ciencia y la filosofía, sino con experiencias y prácticas a través de las cuales afrontamos la única tarea que, en su totalidad, puede tomarse absolutamente en serio sin dejar de divertirnos: la configuración ética de nuestra existencia. La conciencia sobre el carácter propiamente lingüístico de su representación y sobre la ironía de la vida no los obtiene la literatura sólo desde fuera, sino que ella misma, desde el interior de su propia forma, ha conseguido desplegar, con entusiasmo y claridad, la descripción consciente del conflicto por construir su propia identidad. Este conflicto, como contenido de las obras literarias, no aspira sólo al comentario sino que pretende ser configurado como la verdad del arte que, insistimos, no anula sino que convida a afrontar éticamente nuestro destino. A manera de ejemplo de esto, en lo que sigue montamos, mediante citas y comentarios, un ensayo fragmentario. 
Toda palabra es un conjuro. Ese espíritu al que se llama, aparece.

Novalis

El romanticismo alemán es, quizás, el movimiento fundador de la modernidad que con mayor énfasis ha convertido la cuestión de la voluntad literaria y artística en uno de los temas de la literatura misma. A partir del romanticismo la meditación literaria del llamado al arte dio lugar a la consolidación de un género: la novela de artista. ${ }^{1}$ En el mundo representado de la obra literaria se describe la pugna de aquel que, mediante la afirmación de su derecho a crear con la imaginación, se enfrenta al mundo real. El mundo real que aparece en la obra es ya un mundo penetrado por la literatura: el conflicto entre las exigencias establecidas y el artista acontece al interior de la forma literaria permitiendo que en ésta se describa la reflexión vivida del personaje sobre problemas estéticos y éticos.

En las bellas expresiones de la literatura encuentran morada ideas preñadas de emoción que reivindican su derecho a ser conocimiento. De este modo la añeja y siempre compleja relación entre filosofía y literatura se complicó aún más. La literatura ya no era sólo objeto de reflexión filosófica sino que ella misma pretendía sostenerse en una meditación propia. Esta meditación, más allá de un simple traslado de problemas filosóficos a la forma literaria, trata de constituirse en una reflexión cuestionadora de alguna filosofía particular. A manera de ejemplo recuérdese la impronta kantiana en Heinrich von Kleist y la presencia crítica de Fichte en Friedrich Schlegel y Novalis. Por su parte, la filosofía adquirió una mayor conciencia de su labor formadora de conceptos

${ }^{1}$ El modelo es Wilhelm Meister de Goethe. Sin embargo, como bien apunta Georg Lukács, el romanticismo, concretamente Novalis con su Heinrich von Ofterdingen, vio la necesidad de separarse del modelo: "También ante él flotaba como meta de la vida la armonía última del Wilhelm Meister, y con la misma claridad que Goethe veía lo peligroso que habían sido los comienzos y los caminos de aquella peregrinación. A pesar de todo pensaba que Goethe había alcanzado la meta empobrecido, más pobre de lo que exigía la consecución.

En este punto se separa el camino del romanticismo del camino de Goethe. Ambos buscan un equilibrio de las mismas fuerzas divergentes, pero el romanticismo exige un equilibrio en el cual la armonía no debilite la intensidad de ninguna fuerza. Su individualismo es más duro y testarudo, más consciente y sin compromisos que el de Goethe; pero el romanticismo quiere alcanzar la armonía última ampliando ese individualismo hasta los límites extremos". (Georg Lukács, El alma y las formas. Barcelona, Grijalbo, 1975, pp. 85-86). 
como un quehacer fundamentalmente lingüístico y, además, se vio en la necesidad de responder a las críticas de los escritores tal y como hace Hegel en su monumental Estética.

La relación conflictiva entre filosofía y literatura, entre pensar y poetizar acontece a veces en el interior de un mismo individuo creador, tal y como lo prueban los casos de los mismos F. Schlegel y Novalis, y de Goethe, Schiller y Hölderlin. Justo es aclarar, a manera de digresión, que, por una parte, esta confluencia entre literatura y filosofía no es exclusiva de la cultura alemana, ya que también la encontramos en autores de otras tradiciones: Leopardi, Coleridge, Baudelaire, Valéry, Malraux y, en el ámbito de la lengua hispánica, Machado, Gómez de la Serna, Borges, Cuesta, Paz y Xirau por mencionar algunos ejemplos destacados. Por otra parte, en los creadores de buen linaje -como son todos los mencionados- los puentes entre filosofía y literatura no significan nunca una mixtificación en detrimento de ambas: se mantienen los límites, aunque se jueguen con ellos, entre los aspectos figurativo e imaginativo del lenguaje y la reflexión creadora de conceptos.

Dos filósofos que consideran al pensar como un acontecer del lenguaje y a éste nacido de un suelo irreductible a la conciencia son Schopenhauer y Nietzsche. Para Schopenhauer el lenguaje, además de su capacidad cognoscitiva manifiesta en los conceptos científicos ordenadores del mundo fenoménico, puede alcanzar, en tanto poesía, la intuición de las ideas de la vida. En la poesía el lenguaje obtiene el límite de lo representable y en la filosofía se esfuerza por simbolizar conceptualmente lo que queda más allá de toda representación. Nietzsche, por su parte, navegó -y, quizás, naufragósobre la conciencia de que los pensamientos que tenemos son aquellos para los que disponemos de palabras que los pueden expresar aproximadamente y que, por lo tanto, para comprender la escritura no es la literalidad de la palabra lo que debemos atender sino "la música que está detrás de las palabras, la pasión que está detrás de esa música, la persona que está detrás de esa pasión: todo aquello, por tanto, que no puede ser escrito". ${ }^{2}$

Schopenhauer y Nietzsche son también dos pensadores que aprendieron de la literatura e influyeron en ella y en el arte en general. Un heredero de la tradición burguesa clásica y romántica y un interlocutor lúcido de ambos es un apasionado por narrar historias: Thomas Mann, poeta "épico, hijo de las musas al que gusta la minuciosidad". ${ }^{3}$

${ }^{2}$ Friedrich Nietzsche, Aforismos. Ed. de Andrés Sánchez Pascual. Barcelona, Edhasa, 1994, pp. 116-117.

3 Thomas Mann, Sobre mí mismo. La experiencia alemana. Barcelona, Ediciones Paradigma, 1990, p. 48. 


\section{II}

No hay problema más angustioso en el mundo que el de ser artista y el de sus consecuencias humanas.

Thomas Mann

En el despliegue del pensamiento único de Schopenhauer, Thomas Mann advierte "una concepción artística del mundo en la cual no sólo la cabeza participa sino que participa el hombre entero, con su corazón y sus sentidos, con el cuerpo y con su alma". ${ }^{4}$ La presencia de Schopenhauer no sólo es perceptible en los arrebatos líricos de Thomas Buddenbrook fascinado por la muerte como modo de trascender el dolor individual sumergiéndose en la nada del dolor universal, sino que atraviesa toda la obra de Mann, quien, en un ensayo elaborado en la vejez sobre el autor de El mundo como voluntady representación, sigue considerándolo como un pensador con porvenir: “...todo eso que yo he llamado su humanismo pesimista me parece estar lleno de un talante de futuro y promete tal vez todavía a su obra mental una acción humana y fecunda tras una fama causada por la moda y un posterior semiolvido". 5

Nietzsche también es una influencia perdurable en Thomas Mann. Es conocido que ciertos rasgos biográficos e incluso algunas tormentas de pensamiento del discípulo de Dioniso los recrea Mann en su novela cumbre Doktor Faustus. A pesar de esto, el escritor supo apreciar al filósofo manteniéndose a distancia de él. La influencia espiritual de Nietzsche no fue capaz de conseguir modificarlo en lo más intimo de su ser. Y, sin embargo, pocos como Thomas Mann han sabido apreciar la enseñanza moral nietzscheana de aprender a soportar la soledad.

En una palabra -dice Mann en un apunte biográfico publicado en 1940-, yo advertía en Nietzsche, ante todo, al que se vence a sí mismo. No le tomaba nada al pie de la letra, ni le creía, y esto precisamente le daba a mi amor por él ambivalencia y apasionamiento; profundidad [...] Su exaltación de la "vida" a costa del espíritu, esa lírica que tan funestas consecuencias a tenido para el pensamiento alemán, sólo podía entenderla de un modo: como ironía. ${ }^{6}$

De los dos filósofos romántico-tardíos - críticos a la vez de cierto romanticismo- recibe el más clásico de los escritores alemanes de este siglo lo que

${ }^{4}$ T. Mann, Schopenhauer, Nietzsche, Freud. Barcelona, Plaza \& Janés. 1986, p. 27.

${ }^{5}$ Ibid., p. 102.

${ }^{6}$ T. Mann, Sobre mí mismo, pp. 104-105. 
"constituye acaso - como dice Eugenio Trías-su tema filosófico": el arte como mediación del espíritu y la vida. ${ }^{7} \mathrm{Y}$ en su hermoso y breve libro, ejemplo notable de crítica artística, Juan García Ponce - para quien Thomas Mann es "el gran escritor, el supremo artista, capaz de convertir la erudición en poesía y de encontrar la forma que transforma todo en belleza" $-{ }^{8}$ ha mostrado cómo en la obra del autor de $E l$ elegido se presenta una imprescindible reflexión ética y estética. Las narraciones y novelas de Thomas Mann son distintas estaciones de tránsito de un viaje en el que el artista penetra en las profundidades "para hallar los orígenes de los que nace el lenguaje" y formarlo en la obra iluminando la capacidad humana "de tocar el fondo y llevarlo a la luz". Descendiendo al fondo el artista abreva en su vida, en sus propias soledad y desesperación para, con su obra, dar vida y, al mismo tiempo, trascender el lenguaje. Se escribe por la necesidad de formar el fundamento en el lenguaje y para que los hombres puedan encontrar un "luminoso reflejo" que les posibilite la formación de su vida. ${ }^{9}$ El propio Thomas Mann habló alguna vez de su obra como expresión del paisaje musical percibido en el sonido de la tierra; en la lengua.

El sustento estilístico que permite construir la obra de arte como forma mediadora de la contraposición entre espíritu y vida es la ironía. Y quizás nada describe tan atinadamente la presencia de la ironía en la obra de Mann que estas palabras de su amigo -escritor alguna vez muy leído y crítico que merece mayor atención- Hermann Hesse: "Hay días en los que contemplamos el mundo con una mezcla de crítica sobria y melancolía no confesada; en esos días las personas y las cosas nos muestran rostros como los pinta Thomas Mann, tan serios que dan risa y tan cómicos que hacen llorar". ${ }^{10}$ La inteligencia irónica no sólo permite ver y describir sino, además, cuestionar y evaluar lo que se describe: la obra de arte nos muestra un conflicto en el que el narrador está a la vez inmerso y alejado. En esta paradoja de inmersión y alejamiento la belleza y la verdad mantienen una relación y apoyo recíprocos. "Una belleza que no tuviera de su parte la verdad, que no pudiese remitirse a ella, que no viviera de ella y por ella, sería una quimera vacía [...]" ${ }^{11}$ La ilusión artística adquiere dignidad con su anclaje en la verdad y, en tanto verosímil, se aleja de la mentira. Como ejemplo de esto recordemos brevemente el problema que aparece en tres novelas de artista de Thomas Mann.

Después del tremendo éxito de Los Buddenbroks, en 1903 publicó Mann su tercer libro: Tristán, seis novelas cortas. Dos de estas narraciones, la que

\footnotetext{
${ }^{7}$ Eugenio Trías, Conocer Thomas Mann y su obra. Barcelona, Dopesa, 1978, p. 24.

${ }^{8}$ Juan García Ponce, Thomas Mann vivo. México, Era, 1972, p. 10.

${ }^{9}$ Cf. ibid., pp. 13 y 90.

${ }^{10}$ Hermann Hesse, Escritos sobre literatura 2. Madrid, Alianza, 1984, p. 502.

${ }^{11}$ T. Mann, Schopenhauer, Nietzsche, Freud, p. 25.
} 
da título al volumen y Tonio Kröger -escritas simultáneamente según su autor- tratan, como conflicto central, la lucha entre arte y realidad. ${ }^{12}$

Tristán transcurre en un hospital cuyo ambiente preludia vagamente el de La montaña mágica. El escritor Detlev Spinell se encuentra en él debido al estilo Imperio del edificio, ya que este estilo le es, por algún tiempo, absolutamente necesario para obtener un poco de bienestar. Spinell es autor de un único libro al que siempre tiene en la mesa de trabajo. "Las palabras no parecían afluirle en absoluto; al contrario: para ser una persona cuya profesión era escribir, se movía con lastimosa lentitud, y quien le hubiera visto habría llegado sin duda a la conclusión de que el escritor era un hombre al que el escribir le resulta más difícil que a las demás personas”. Spinell es un estrafalario y solitario al que sólo la contemplación estética es capaz de producirle un humor festivo. Para esto le basta percibir una "borrosa sombra" y estimular su fantasía para forjar la ilusión de la belleza. No obstante o, mejor dicho, precisamente por esto no carece de conciencia sobre la inutilidad propia de su vocación: hacer hablar a las cosas otorgándoles el nombre adecuado; expresar lo que es dándole conciencia en las palabras sin importar las consecuencias de ello. La ilusión de la belleza creada por Spinell se derrumba cuando éste contempla la belleza real: el rostro de la pianista Klöterjahn. Logra colmar su mirada en ella sólo para descubrir un pequeño signo de aniquilación imperceptible, al parecer, hasta para los propios médicos. El grado de enfermedad de la bella señora hace inminente la muerte. Ésta parece apresurar su llegada desde el momento en que la pianista se decide a manifestar la belleza latente bajo sus dedos. Sus interpretaciones al piano de algunos Nocturnos de Chopin y, por supuesto, de Tristán e Isolda de Wagner son, para Spinell, un viaje a la belleza misma. Después de esto, para la pianista, no hay posibilidad de retornar a la vulgaridad de la vida. Aquí el papel del escritor se limita a contemplar y comprender la tragedia de la belleza que él mismo es incapaz de figurar o al menos sugerir en el lenguaje.

Lo insólito de ser capaz de crear belleza y comprenderla parece darse en Tonio Kröger. Tonio Kröger es también un artista; un hombre entregado por completo al "poder del espíritu y de la palabra" lo que le permite tal agudeza en la mirada que abre y entra en el alma de los hombres y clarifica la suya. Esta mirada espiritual "le mostraba el interior del mundo y todo lo que se esconde tras las palabras y los hechos. Y todo lo que vio fue ridiculez y miseria, miseria y ridiculez". Con su atormentado y orgulloso conocimiento vino la soledad pero no la melancolía: se salvaba de ella mediante el placer de construir frases. Se entregó a la bohemia y el decaimiento de la vida "afirmaba más y más

12 Cf. Roman Karst, Thomas Mann. Historia de una disonancia. Barcelona, Barral, 1974, p. 72. 
su cualidad artística”. Para él la vida estaba reñida con la creación y, por lo tanto, ésta debía desechar las sensaciones ya que "sólo es artístico la excitación y el frío arrobamiento de nuestro corrompido sistema nervioso". Así Kröger considera que la literatura es una maldición que aleja de la vida, que aparta de lo humano. No se puede comprender al mundo sin ser un extraño en él. Kröger, en un diálogo o, mejor dicho, en un monólogo que sostiene en las objeciones y divertimentos de su amiga la pintora Lisaveta Ivanovna, exclama: "Comprenderlo todo, ¿significaría perdonarlo todo? No lo sé. Hay algo que yo llamaría náuseas del conocimiento, Lisaveta; es el estado en el que le basta al hombre comprender una cosa para sentirse enseguida mortalmente asqueado, sin posibilidad de reconciliarse con ella [...]" Y precisamente desde aquí se muestra la ironía de la tragedia de Tonio Kröger: a pesar de su instalación en el espíritu él ama la vida decente y amable; trivial. Esa vida que se le presenta extraña e imposible ahora que él no es más que: "Aniquilamiento; soledad; hielo; iy espíritu! ¡Y arte!”

Tonio Kröger, el burgués descarriado, ha enmendado el camino con su transmutación literaria en Gustav Aschenbach, el personaje de La muerte en Venecia aparecida en 1912. Esta obra, según el propio autor, es su "plasmación más acusada y elaborada, en lo moral y lo formal, del problema de la decadencia y el arte". ${ }^{13}$ Artista que goza de la gloria oficial, Aschenbach es un burgués considerado y respetado que vive en armonía con la época, con la cultura, con el Estado. Y, quizás por lo mismo, su soledad es más acentuada aún que la de Tonio Kröger. "La soledad engendra lo original, lo atrevido y lo extraordinariamente bello: la poesía. Pero engendra también lo desagradable, lo inoportuno, absurdo e inadecuado". Aschenbach, creyéndose ubicado en el dominio de sí mismo, ha perdido la dicha del escritor, es decir, la posibilidad de transformar la idea en sentimiento y el sentimiento en idea. Desde esta pérdida, la soledad dispone su destino trágico ya no en la creación sino en los arrebatos de la pasión. Con el trasfondo de una Venecia pestilente, Aschenbach se consume en su pasión por un hermoso joven polaco al que en sus delirios, propiciados por Eros, imagina una repetición de los mancebos griegos a los que Sócrates educaba instándolos a elevarse hasta la contemplación de la belleza pura.

En La muerte en Venecia la pasión irrumpe destruyendo una vida aparentemente formada. Esta vida es la de un artista al que la pasión arroja al absurdo impidiéndole recobrar la dignidad. ${ }^{14}$ ¿Quiere esto decir que el arte como mediación entre el espíritu y la vida no conduce más que a la muerte? En una conferencia sobre Lessing, pronunciada en 1929, Thomas Mann dijo: "Un

\footnotetext{
13 T. Mann, Sobre mí mismo, p. 70.

${ }^{14}$ Cf. ibid., p. 68.
} 
arte cuyo instrumento es la lengua siempre producirá una labor crítica en sumo grado, ya que la lengua en sí es crítica de la vida: nombra, acierta, designa, describe y dirige, porque da vida". ${ }^{15}$ Desde su función principal, vivificar el lenguaje, la literatura puede propiciar el conocimiento y la formación de uno mismo. Al inventar la realidad el escritor puede proveer de imaginación ética nuestra experiencia.

Thomas Mann entiende a la existencia individual como voluntad de concentración y delimitación frente a la nada; en este sentido existir es ya

[...] una decisión moral de ser y sufrir. Sí, ser es ya moral; ¿y qué significaba aquella frase cristiana que dice: "Nuestro mayor pecado es haber nacido"? Sólo la mediocridad piensa que pecado y moral son conceptos antagónicos: en realidad, son uno solo. Sin el reconocimiento de los pecados, sin la entrega a lo pernicioso y disolvente, la moral no es más que santurronería. El estado deseable en el sentido moral no es la pureza y la inocencia; no es la precaución egoísta y el arte desdeñable de la tranquilidad de conciencia lo que constituyen la moral, sino la lucha y el sufrimiento, la pasión y el dolor. ${ }^{16}$

Asumir esta dimensión de la vida y llevarla al arte es la moral del artista; es la concentración de todo esfuerzo en formar la obra como algo que nace del conocimiento y la pasión. Así, el propio proceso creador del arte refleja la moral como afirmación de la vida. "La moral es, sin duda, la más sublime ambición de la vida, tal vez sea la voluntad misma de vivir". ${ }^{17}$ Esta consideración la obtiene Thomas Mann de sí mismo; de su propia creación como ejercicio de conocimiento y transformación.

La cualidad de meterse en tormentas y temblores creados por él y poder salir de ellos la comparte Thomas Mann con Goethe. No obstante, ambos son como la vela que para mantener la llama se tiene que consumir a sí misma.

En el magnífico ensayo ya mencionado de García Ponce se destaca cómo Tonio Kröger al entregarse al arte y negar la vida se vuelve al lenguaje como fundamento. El arribo de Kröger a este conocimiento lo enfrenta al problema de cómo hacer arte cuando se ha negado la realidad del mundo externo. La respuesta está en la narración como conflicto que se narra a sí mismo: el artista es el ser que les presenta a los hombres una verdad que es mera representación. ${ }^{18}$ Y esta verdad sólo es una posibilidad de afrontar con imaginación la tarea de formarnos.

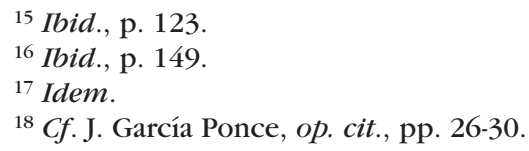


La vida, el mundo -ese mundo al que para mostrar mejor nuestra perplejidad llamamos real-, no es más que un deplorable cúmulo de calamidades. "Y pese a todo - responde Thomas Mann- se trabaja, se cuentan historias, se modela la verdad y se deleita con ello a un mundo indigente, con la confianza casi, de que verdad y forma agradable puedan tener efectos de liberación espiritual y preparar al mundo para una vida mejor, más hermosa, más conforme al espíritu" ${ }^{19}$ Desde la forma propia de la obra de arte, la lucha entre el espíritu y la vida se desborda y su exceso anima a asumirla, ya no sólo en el ámbito de la representación estética, sino en los conflictos con que formamos nuestra experiencia ética de la vida. Asediado el espíritu por el dolor, debemos tender a formar nuestra vida, desde la inestabilidad que le es inherente, en la tensión de conocimiento y pasión, bien y mal, verdad y belleza.

19 T. Mann, "Ensayo sobre Chejov", apud Hans Mayer, La literatura alemana desde Thomas Mann. Madrid, Alianza, 1970, p. 18. 